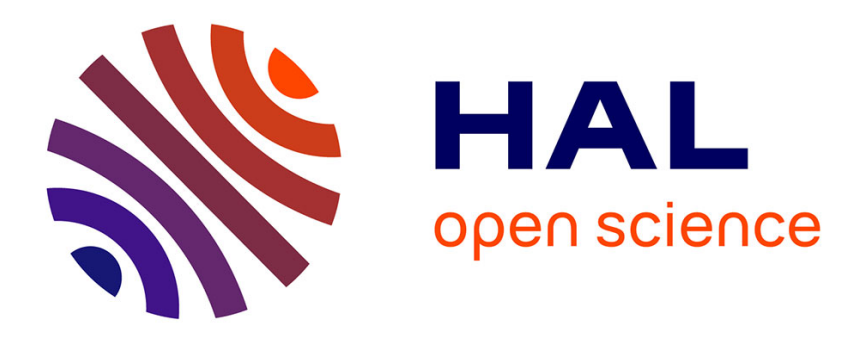

\title{
Epidemics of rules, information aggregation failure and market crashes
}

Kartik Anand, Alan Kirman, Matteo Marsili

\section{To cite this version:}

Kartik Anand, Alan Kirman, Matteo Marsili. Epidemics of rules, information aggregation failure and market crashes. 2010. halshs-00545144

HAL Id: halshs-00545144

https://shs.hal.science/halshs-00545144

Preprint submitted on 9 Dec 2010

HAL is a multi-disciplinary open access archive for the deposit and dissemination of scientific research documents, whether they are published or not. The documents may come from teaching and research institutions in France or abroad, or from public or private research centers.
L'archive ouverte pluridisciplinaire HAL, est destinée au dépôt et à la diffusion de documents scientifiques de niveau recherche, publiés ou non, émanant des établissements d'enseignement et de recherche français ou étrangers, des laboratoires publics ou privés. 


\section{GREQAM}

Groupement de Recherche en Economie Quantitative d'Aix-Marseille - UMR-CNRS 6579

Ecole des Hautes études en Sciences Sociales Universités d'Aix-Marseille II et III
Document de Travail $n^{\circ} 2010-55$

Epidemics of rules, information aggregation failure and market crashes

Kartik Anand

Alan Kirman

Matteo Marsili

December 2010 


\title{
Epidemics of rules, information aggregation failure and market crashes
}

\author{
Kartik Anand ${ }^{1}$, Alan Kirman ${ }^{2}$ and Matteo Marsili ${ }^{1}$ \\ ${ }^{1}$ The Abdus Salam International Center for Theoretical Physics, Strada Costiera 11, 34014 Trieste, Italy \\ ${ }^{2}$ GREQAM, Université de la Méditerranée, 2 Rue de la Vieille Charité, 13236 Marseille, cedex 02, France
}

\begin{abstract}
This short paper argues that rationally motivated coordination between agents is an important ingredient to understand the current economic crisis. We argue that changes in parameters that model the structure of a macro-economy or financial markets are not exogenous but arise as agents adopt rules that appear to be the norm around them. For example, if a rule is adopted by the majority of ones' neighbors it will become acceptable or, alternatively, if agents learn that changing their rule leads to greater gains, they will modified their rules. However, as rules develop and spread they may have consequences at the aggregate level which are not anticipated by individuals. These rules may be adopted by implicit consensus as they turn out to be profitable for individuals, but they may also weaken the constraints imposed by regulators. Indeed, the emergence of new rules or the modification of old ones may render the whole system more fragile, which may then cease to function. To illustrate this we develop a simple model, motivated by the 2007-2008 crisis in credit derivatives markets, to show how coordination on simple and apparently profitable rules may cause a market to collapse.
\end{abstract}

\section{Introduction}

The standard vision of the economy, enshrined in modern macroeconomic models, remains one characterized by a static equilibrium state or where the economy is in a steady state to which it returns when perturbed by an external shock. If the economy deviates suddenly and considerably from such a state this can only be, according to the paradigm, due to a major exogenous shock. This paper argues that such a framework is inappropriate, examines briefly the mechanics of the current crisis and then proposes a simple model to show how the adoption of locally rational rules by the participants in a market can lead to a collapse at the aggregate level.

Before proceeding it is worth looking at the standard equilibrium approach. A first problem with that view is that many models of the economy are characterized by multiple equibria (for a comprehensive survey see Cooper (1999)). A seminal paper by Morris 
and Shin (2000) argued that radical changes or shifts between equilibria may result as a consequence of small modifications in the structure of the system. This evolution may not be simply reversible ${ }^{1}$. Such phase transitions cannot be corrected by remedial policies since there is no steady state or equilibrium path but rather an evolution through a set of states.

A second question concerns the origin of shifts in a models' parameters. As stated, we have become accustomed in the macroeconomic literature to the idea that periodically exogenous shocks temporarily knock the economy off course but that it eventually returns to the steady state path. This vision has led to the study of impulse response functions ${ }^{2}$, which are supposed to measure the consequence of the external shocks.

However, none of this fits well with accounts of the evolution of the recent sub-prime crisis which we outline in the next section. In those accounts, words such as trust, contagion and network are commonly used. Each of these terms suggests that we have to consider the economy as an interactive system, which does not mean that markets cease to exist or be important, but that peoples behavior in these markets is conditioned by the behavior of others around them. This is what Shiller (2008) refers to as social contagion. Furthermore, this evolution does not require a class of dishonest individuals who break the existing rules or norms because doing so is to their advantage and they have fewer scruples than their honest counterparts. In such a case one might just reflect on more effective regulatory systems to control and punish such behavior. What is, in fact at work, is the process by which what is acceptable changes, and it is this that underlies the collapse of such systems. In all of this there is no villain, no proximate cause, just a system evolving with a collective logic which does not correspond to that of the people who make it up.

In the next section we draw from recent accounts on the crisis in credit derivatives which suggests that the diffusion of a certain type of behavioral rules among market participants has played a major role. In brief, two self-reinforcing concomitant factors were at play: On one side, the financial system was becoming less and less transparent. On the other, market participants had fewer and fewer incentives to gather correct information, given the increased costs of information and the apparent liquidity of the market. In the following section we develop a simple model which reproduces this feedback mechanism. In the model, the participants in a market for securitized assets are led to buy without verifying the quality of the underlying assets, on the basis of their assessment of the likelihood that others will buy these assets anyhow. We show that, as this practice develops the whole system may finally break down. The final section discusses the results and offers some concluding remarks.

\footnotetext{
${ }^{1}$ Economists are familiar with the idea of a system which evolves along a surface and then may, as a result of a continuous change in variables slide suddenly on to a different surface. The applications of catastrophe theory and later chaos theory to economics are illustrative of this (see Rosser (2000)).

${ }^{2}$ see, for example, Dridi et al. (2007) and Hall et al. (2009).
} 


\section{The sub-prime crisis}

The outbreak of the sub-prime financial crisis, which can be dated to March 2007 with the revelation of losses by United States sub-prime investors Accredited Home Lenders Holding and New Century Financials, is similar to the bursting of previous asset bubbles. A number of in-depth studies have been produced since that time ${ }^{3}$. The following sketch highlights how particular rules for economic activity took root and addresses the deeper question, raised by Eichengreen (2008), which is "how this belief in the efficacy of selfregulation was allowed to develop?"

Over the last thirty years there has been an explosion in the availability of credit for home-owner and entrepreneurs in the United States. This burst has been fueled by innovation in the financial sector and in particular by the advent of securitization. Following Fabozzi and Kothari (2007), we now briefly sketch the process. We identify as the originator a bank, or any financial intermediary, with a portfolio of assets on its' balance sheet. These assets represent loans to home-owner and entrepreneurs who make regular installment payments (receivables) to the originator to clear their debts. A pool of these assets are selected and transferred to a special purpose entity (SPE), who pays for them by issuing securities. These securities are rated by credit agencies and bought by investors, who are paid back by the SPE from the stream of receivables. Investors are allowed to trade these asset backed securities (ABS) with others in a secondary market.

Securitization gained popularity amongst banks as it allowed them to diversity theirs risks to a host of investors by the issuance of ABS via the SPE. As a result, banks were able to remove assets from their balance sheet. This, in turn, meant that their capital requirements - money that must be set aside to cover potential losses - were lower, thereby shoring up their liquidity and investment capabilities.

The growth of the ABS issuance has been nothing short of meteoric. As noted by Adrian and Shin (2009) in the second quarter of 2007, the total assets held by issuers of ABS in the United States - which the authors collectively refer to as the shadow banking system - was approximately sixteen trillion dollars and substantially larger than those held by banks, which totaled approximately twelve trillion dollars. The growth rate of assets for ABS brokers, especially since the mid 1980's, has far exceeded those of commercial banks to the point that the vast majority of home-owner mortgages are held within the shadow banking system. As more and more prime rated home-owner took on mortgages, the banks, being awash with liquidity, were more freely willing to underwrite mortgages for home-owners rated sub-prime. Paradoxically, as further discussed by Adrian and Shin (2009), many of the purchasers of the securities turned out to be the banks themselves.

We identify some of the factors that contributed to this exponential growth as follows.

\footnotetext{
${ }^{3}$ See, for example, Ashcraft and Schuermann (2008); Dell'Ariccia et al. (2008); Acharya and Richardson (2009); Adrian and Shin (2009); Hume and Sentance (2009) and Smaghi (2010).
} 
- Investors adopted an decision rule whereby investments were made solely on the basis on publicly available signals and without performing independent credit analysis. Partly this was due to over-reliance on the information provided by rating agencies ${ }^{456}$.

- The secondary market for ABS - and mortgage based securities (MBS), in particular - was generally perceived to be liquid ${ }^{7}$. Hence buying MBS became acceptable, under the assumption that others considered MBS to be liquid (and hence tradable). This in turn reinforced the assumption that MBS were liquid. Therefore, as more and more investors adopted this rule i.e., trading in ABS without conducting independent credit analysis, it became profitable for others to follow suit and adopt the same rule in turn.

- A similar failure in information gathering also characterized the sub-prime mortgage market (see Rajan et al. (2008)). The increased distance between risk origination (the sub-prime borrowers) and risk bearers (investors holding the ABS), induced intermediaries to grant sub-prime loans without appropriate due diligence concerning the reliability of borrowers. In other words, the network linking lenders and borrowers grew and evolved to increase opacity in the system. Despite the increased connectivity and density, information did not flow.

\footnotetext{
${ }^{4}$ The role of credit agencies in facilitating the smooth operation of financial markets may be summarized as correcting the problem of asymmetric information, first analyzed explicitly, in the context of a usedcar market by Akerlof (1970). The issuer of an ABS typically has more information on the value of the underlying asset, and hence its price, but does not share this information with the buyer. Instead, the buyer is quoted a certain price and must determine whether this reflects the true value. Rating agencies, as independent third-party entities should, in principles, circumvent the conflict of interest between buyers and sellers by providing an impartial assessment of the asset. In practice, however, rating agencies are not paid for their services by the investors but instead by the issuers of these securities. Thus, contrary to the original concept, there is a direct conflict of interest which leads to a friction whereby investors are unable to determine whether the rating agencies are being honest or not. Indeed, similar questions as to the moral hazards for rating agencies were raised (see Cheung and Tam (2009)) in the aftermath of the East-Asian crisis of 1997. A detailed analysis of the various effects related to asymmetric information and moral hazard is provided by Ashcraft and Schuermann (2008).

${ }^{5}$ The Financial Stability Forum (2008) observed that "[...] some institutional investors have relied too heavily on ratings in their investment guidelines and choices, in some cases fully substituting ratings for independent risk assessment and due diligence." As a reaction to this document, some organizations (like the European Fund and Asset Management Association) laid out guidelines to avoid the over-reliance on ratings agencies.

${ }^{6}$ In September 2009, the U.S. Securities and Exchange Commission (2009), voted to regulate ratings agencies better. The chairman of the Commission, Mary Schapiro, said, "These proposals are needed because investors often consider ratings when evaluating whether to purchase or sell a particular security. That reliance did not serve them well over the last several years." See also Adrian and Shin (2009).

${ }^{7}$ The Bond Market Association, an organization which does not exist any longer, issued an "Investor's guide to mortgage backed securities" in 2002, which explicitly declared that over-the-counter markets for MBS and credit-card based securities were liquid markets. See also Sabarwal (2006).
} 
These conditions coupled with the spread of such seemingly rational rules amongst investors, led to a failure of markets to aggregate signals and reveal information on the fundamental value of assets. As a result, investors, seemingly blindly, bought into the ABS market and unwittingly assumed far greater risks.

Indeed, the dire consequences of these developments were made painfully apparent when the sub-prime mortgage bubble burst and a financial crisis developed. As economic conditions in the United States started to cool down in the mid 2000's, in response to contractionary monetary policy, defaults on mortgages in the sub-prime sector increased. This together with the impact of the resultant decline in real-estate prices meant that it became more difficult to re-sell the property to recoup the original value. This, in turn meant that the price of all the securities diminished since it was not clear which were "toxic". As the prices of securities plummeted, investors started losing trust in the future profitability of the issuers of securities and chose instead to horde their liquidity. This resulted in a freeze of the credit and credit derivatives markets, thereby causing a large increase in ABS spreads.

This story of asymmetric information and herding of investors is endemic to all previous asset-pricing and credit bubbles, including the 1920's telecommunication, as recounted by Eichengreen and Mitchener (2003), and the 1990's dot-com boom and subsequent burst. In the most recent crisis it has become clear that the problem was exacerbated by the collective "decision" not to gather information.

\section{The model}

Our goal is to model the general mechanism whereby investors, as a rule, trade securities without giving due diligence to fundamental information. The rationale motivating investors is simply that it is profitable to adopt this rule, because other investors have already adopted it.

The system consists of $i=1, \ldots, N$ agents, which, in the case of the sub-prime crisis, we can think of as the banks who were both the issuers- via SPEs - and the investors in these ABS. Each agent $i$ is characterized by a variable $z_{i} \in\{0,1\}$ which specifies whether she follows $\left(z_{i}=1\right)$ or not $\left(z_{i}=0\right)$ the following behavior, or rule for short:

purchase an ABS, relying on signals from the rating agencies, without independently evaluating the fundamental value of underlying assets

Succinctly, we write

$$
z_{i}=\left\{\begin{array}{l}
1 \text { if agent follows the rule } \\
0 \text { if agent performs independent risk analysis }
\end{array}\right.
$$

The rationale for adopting the rule, as we will see, is not based on the fundamental quality of the asset but rather on the fact that others also follow the rule. If, in fact, 
enough other participants do so, the agent becomes convinced, not irrationally that the ABS is highly liquid and hence easy to trade.

Let us assume that the ABS is toxic with probability $p$. By toxic we mean, for example, that the underlying asset was incorrectly graded and that the original borrower of loan has already defaulted or has a higher probability of defaulting. The cost of purchasing a security is $c<1$ whereas the payoff from successfully re-selling the security is normalized to unity ${ }^{8}$ :

\begin{tabular}{c|c|c} 
& check \& toxic & no check \\
\hline$z_{i}=1$ & $-c$ & $1-c$ \\
\hline$z_{i}=0$ & $-\chi$ & $1-c-\chi$
\end{tabular}

Agents are linked together with trading partners in a financial network. Let $N_{i}$ be the set of neighbors ${ }^{9}$ of agent $i$ and $k_{i}=\left|N_{i}\right|$ its cardinality. This captures the fact that the secondary market for trading ABS and other credit derivatives is not centralized but instead takes place over-the-counter with traders in one firm directly calling up other traders to sell their securities (see Sabarwal (2006)). The limit where $N_{i}$ coincides with the set of all agents corresponds to the case of a centralized market.

When agent $i$ receives an offer to buy new ABS, she considers whether or not to follow the rule. The line of reasoning she pursues is to first determine the probability that, if she adopts the rule and subsequently attempts to re-sell the security, the potential buyer, agent $j$ will refuse to buy the security. This will be because agent $j$ does not follow the rule and, as such, may verify that the underlying asset is toxic and, hence, not liquid. In this event, agent $i$ will incur a loss of $c$ with probability $p\left(1-z_{j}\right)$, where $j \in N_{i}$ is the index of the potential buyer. The expected payoff to $i$ from following the rule, i.e., $z_{i}=1$, is

$$
\begin{aligned}
u_{i}\left(z_{i}=1\right) & =E\left[-p\left(1-z_{j}\right) c+\left[1-p\left(1-z_{j}\right)\right](1-c)\right] \\
& =1-p\left(1-\bar{z}_{i}\right)-c
\end{aligned}
$$

where $\bar{z}_{i}=\mathbb{E}\left[z_{j}\right]$ is the expected value of $z_{j}$ for $j \in N_{i}$. We assume that the probability $p$ that assets are toxic is known to agents ${ }^{10}$. When agent $i$ buys the asset, she does not know ex ante to whom she will sell the security nor which neighbors follow the rule. In other

\footnotetext{
${ }^{8} \mathrm{~A}$ more detailed derivation of the payoffs is as follows: An agent buys a security at price $p_{0}$. If she re-sells it right away, i.e., the subsequent buyer follows the rule or she performs the risk analysis and verifies that the asset is not toxic, the security is sold for the price $p_{1}>p_{0}$. Hence the payoff in this case is $1-c=p_{1}-p_{0}$. If she does not sell, she will nevertheless receive future coupon payments from the issuer of the security. However, discounting for degradations in the assets' rating and also time, the effective price of the security held by the agent is $p_{2}<p_{0}$ and hence the payoff is $-c=p_{2}-p_{0}$. If one takes $p_{1}=1+p_{2}$ and $p_{0}=p_{2}+c$ this is the model in the main text. This choice has the advantage of reducing the number of parameters by one.

${ }^{9}$ The network may be directed as the set of traders agent $i$ buys from need not be the same set to whom she sells securities.

${ }^{10}$ The case where agents rely on over-optimistic estimates of default probabilities, such as those issued by rating agencies, can be dealt with easily. The final section comments briefly this issue.
} 
words, agent $i$ cannot observe the type $z_{j}$ of her neighbors, but can instead estimate the probability $\bar{z}_{i}$ that a buyer in her neighborhood follows the rule. For simplicity, we take

$$
\bar{z}_{i}=\frac{1}{k_{i}} \sum_{j \in N_{i}} z_{j} .
$$

The expected payoff to agent $i$ from not following the rule is $u_{i}\left(z_{i}=0\right)=(1-p)(1-$ $c)-\chi_{i}$. Here $\chi_{i}>0$ is the cost of gathering information. The rationale here is that, if agent $i$ determines the asset to be toxic, she will only incur the cost of performing the risk analysis. If the asset turns out not to be toxic, with probability $1-p$, she will be able to easily re-sell the security and hence the payoff is $1-c-\chi_{i}$.

In sum, the best response of agent $i$, when she gets the opportunity of buying a new ABS is: ${ }^{11}$

$$
\begin{aligned}
z_{i}^{*} & =\Theta\left[u_{i}(1)-u_{i}(0)\right] \\
& =\Theta\left[p\left(\frac{1}{k_{i}} \sum_{j \in N_{i}} z_{j}-c\right)+\chi_{i}\right]
\end{aligned}
$$

We model the dynamics, starting from any given set of initial conditions for $z_{i}$ as follows. At each time $t$, we randomly select agents $i$ and $j$ whereby $i$ receives an offer to buy an ABS from $j$. Agent $i$ updates her value of $z_{i}$ as the best response $z_{i}^{\prime}=z_{i}^{*}$. This dynamics goes on until the population reaches a fixed point.

In order to probe the stochastic stability of fixed points, it is useful to generalize the dynamics introducing a probabilistic choice model. A standard way of introducing such stochastic trembles ${ }^{12}$ consists in replacing Eq. (4), in the dynamics, by a probabilistic choice of the logit type:

$$
P\left\{z_{i}=1\right\}=\frac{e^{B u_{i}\left(z_{i}=1\right)}}{e^{B u_{i}\left(z_{i}=0\right)}+e^{B u_{i}\left(z_{i}=1\right)}} .
$$

The parameter $B$ modulates the randomness in the choice and is often referred to as intensity of choice. In the limit $B \rightarrow \infty$ the choice model Eq. (5) reduces to Eq. (4).

Numerical simulations based on the dynamics with both Eq. (4) and Eq. (5), are presented in Fig. 1. The state where everybody follows the rule $\left(z_{i}=1, \forall i\right)$ is a fixed point of the $B \rightarrow \infty$ dynamics for all values of $p$. Indeed, when everybody follows the rule,

\footnotetext{
${ }^{11} \Theta(x)=1$ for $x>0$ and $\Theta(x)=0$ otherwise.

${ }^{12}$ This model has been also proposed in order to capture the trade-off between exploration of new rules and exploitation of already found ones by Weisbuch et al. (1998).
} 


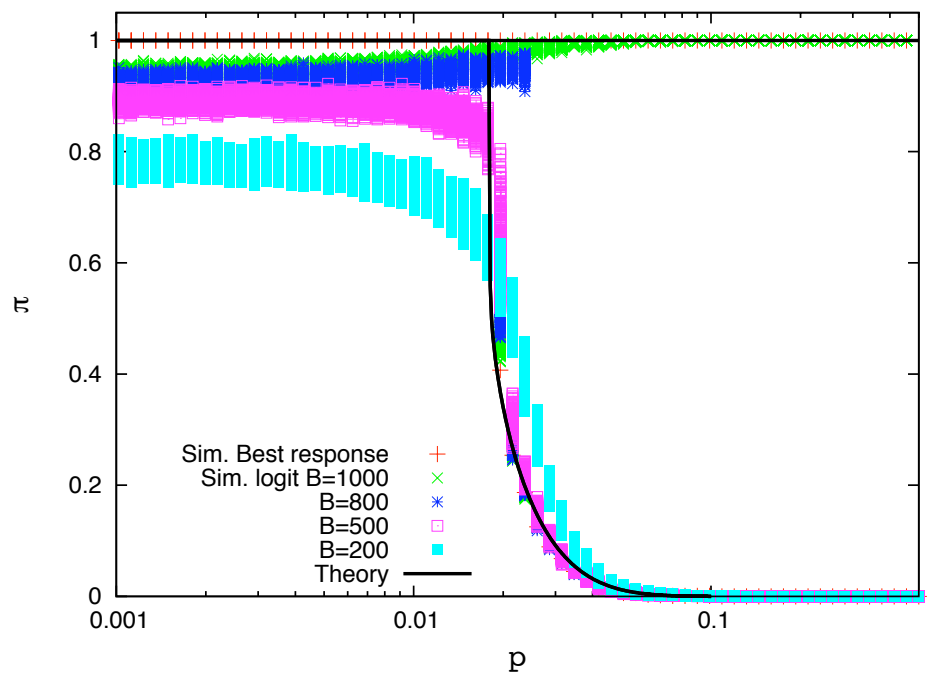

Figure 1: Prevalence $\bar{\pi}=E[z]$ of rule followers, as a function of $p$, for a model with $c=0.9, k=11$ and an exponential distribution of $\chi_{i}$ with mean 0.01 . The results of numerical simulations (best response) are compared with the theory (full line). Results for noisy best response $P\left\{z_{i}=1\right\}=e^{B u_{i}(1)} /\left(e^{B u_{i}(1)}+e^{B u_{i}(0)}\right)$, with $B=200,500,800$ and 1000 are also shown.

no trade is ever refused, independently of the quality of the assets, precisely because no-one checks for it. For large values of $p$, however, this fixed point coexists with one where most of the agents perform their independent credit analysis $\left(z_{i}=0\right)$.

Fig. 1 also shows, however, that the rule dominated equilibrium loses stability for high $p$, if the intensity of choice parameter $B$ is not large enough. For intermediate vales of $B$, as $p$ increases, one has a sharp transition from the state where the vast majority follows the rule, to a situation where most of the agents don't.

To appreciate how this model leads to herding, imagine starting from a market in which there are only fundamentalists, i.e., no one follows the rule $\left(z_{i}=0 \forall i\right)$. Those agents with cost $\chi_{i}>p_{c}$ will find it profitable to adopt the rule. A large cost may be understood as the securities being very complex, for example after multiple repackaging. This, in turn, this will make it appear to be profitable for some of their neighbors to also follow the rule and similarly for the neighbors of these neighbors. If the rule spreads to the extent that $\bar{z}>c$ all agents, even those for whom information is available for free, will follow the rule, then no one will look for information.

\subsection{Mean field analysis}

We may shed further light on the results of numerical simulations using a mean field analysis for the theory. We limit our analysis to the case where $B \rightarrow \infty$. Furthermore, we consider, for the sake of simplicity, a network with homogenous degrees, i.e., $k_{i}=\left|N_{i}\right|=k$. 
Defining $\pi(\chi)=P\left\{z_{i}=1 \mid \chi_{i}=\chi\right\}$ to be the probability that agent $i$ follows the rule, given a cost for information equal to $\chi$, we have that

$$
\pi(\chi)=\sum_{\ell>(c-\chi / p) k}\left(\begin{array}{l}
k \\
\ell
\end{array}\right) \bar{\pi}^{\ell}(1-\bar{\pi})^{k-\ell}, \quad \bar{\pi}=E_{\chi}[\pi(\chi)] .
$$

The probability that a randomly chosen neighbor of agent $i$ follows the rule is given by $\bar{\pi}$. Considering Eq. (4), the probability that $i$ adopts the rule is simply the probability that at least $(c-\chi / p) k$ other neighbors follow the same rule.

Taking the expectation of Eq. (6) over costs $\chi$ one gets the following self-consistent equation for $\bar{\pi}$.

$$
\begin{aligned}
\bar{\pi}=F(\bar{\pi}) & =\mathbb{E}_{\chi}\left[\sum_{\ell>(c-\chi / p) k}\left(\begin{array}{l}
k \\
\ell
\end{array}\right) \bar{\pi}^{\ell}(1-\bar{\pi})^{k-\ell}\right] \\
& =\sum_{\ell=0}^{k}\left(\begin{array}{l}
k \\
\ell
\end{array}\right) \bar{\pi}^{\ell}(1-\bar{\pi})^{k-\ell} P\{\chi>p(c-\ell / k)\} .
\end{aligned}
$$

The solution of these equations are shown in Fig. 2 for different values of $p$, where for small $p$, the solution $\bar{\pi}=1$ is the only fixed point. For $p>p_{c}$ the fixed point $\bar{\pi}=0$ appears, with a basin of attraction (the interval in $\bar{\pi}$ where $F(\bar{\pi})<\bar{\pi}$ ) that grows with $p$. However, noting that since $F(\bar{\pi}=1)=1$, the fixed point $\bar{\pi}=1$ is, in fact, always a solution.

The mean field solution accurately matches the results of numerical simulations, as shown in Fig. 1. The costs $\chi_{i}$ are drawn from an exponential distribution. For this choice, it is possible to obtain further results in the limit $k \gg 1$, where we approximate the binomial distribution with a delta-function of $\ell / k-\bar{\pi}$. Consequently, Eq. (7) reduces to

$$
\bar{\pi} \cong P\{\chi>p(c-\bar{\pi})\}=\min \left\{1, e^{\lambda p(c-\bar{\pi})}\right\},
$$

where $1 / \lambda$ is the mean value for the exponential distribution of costs $\chi_{i}$. The solution with $\bar{\pi}<1$ exists for large $p$ and it ceases to exist when $F^{\prime}(\bar{\pi})=1$. The latter equation, combined with $\bar{\pi}=F(\bar{\pi})$, implies that the boundary of the coexistence region is given by the equation

$$
\lambda p=e^{\lambda p c-1}
$$

and, more precisely, by the largest root (in $p$ ) of this equation. This is shown in Fig. 3. 


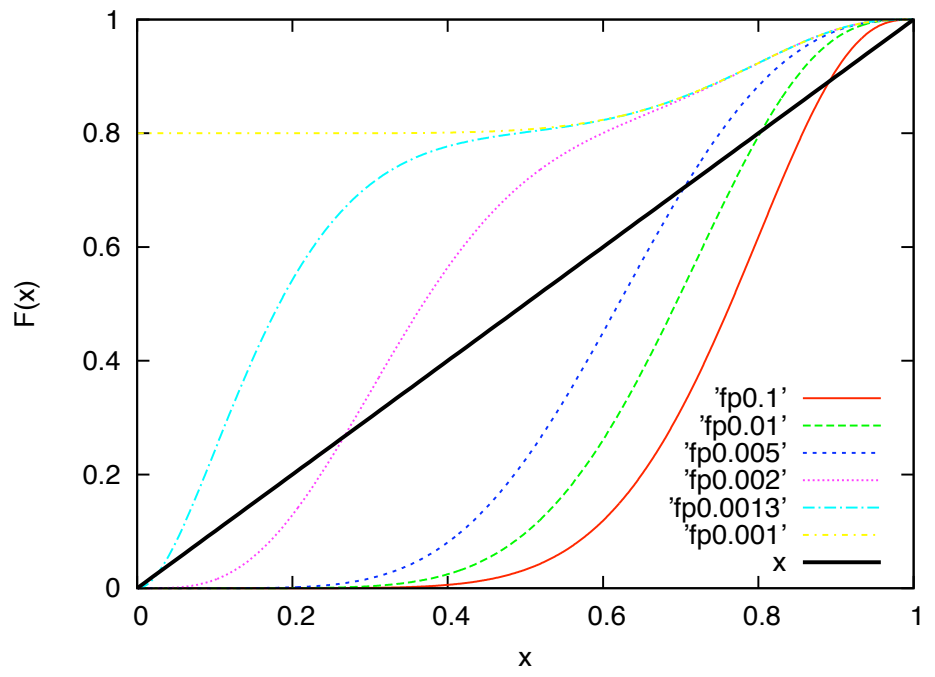

Figure 2: Function $F(\bar{\pi})$ in the rhs of Eq. (7), as a function of $\bar{\pi}$, for different values of $p$ $(0.1,0.01,0.005,0.002$ and for 0.001$)$. Here $\chi=\chi_{0}=0.01$ for $80 \%$ of the population, whereas the remaining minority has $\chi=0 . k=11$ and $c=0.8$. For this particular choice of the distribution of $\chi_{i}$, the phase diagram is shown in Fig 3.

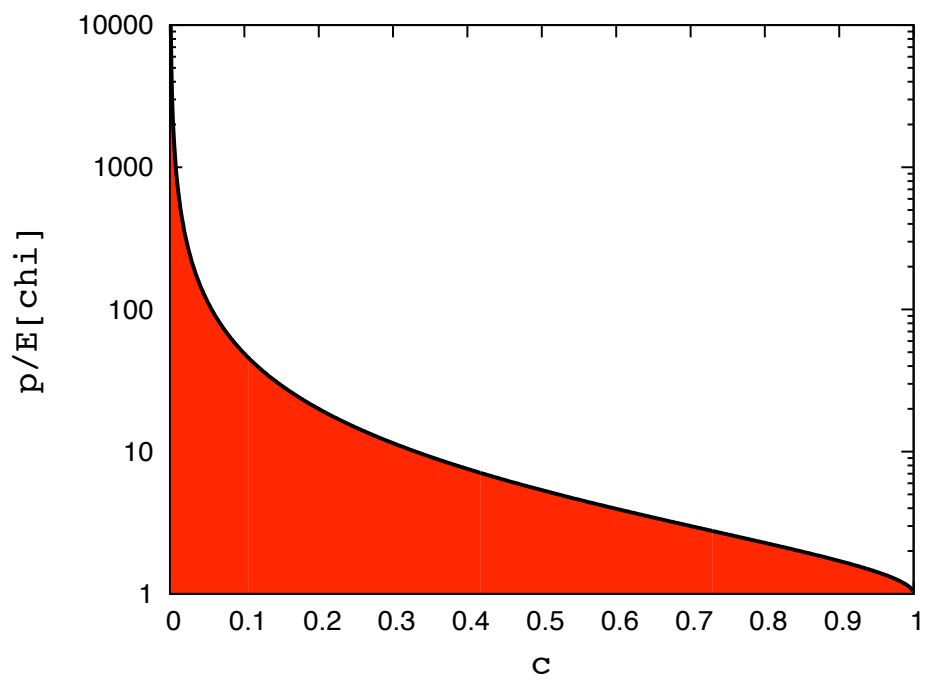

Figure 3: Phase diagram in the $(c, p / E[\chi])$ plane for a model with an exponential distribution for $\chi$. 


\section{Discussion}

It has been forcefully argued by Shiller (2008) and others that, by 2007 considerable evidence as to the bad credit quality of sub-prime based ABS had been steadily accumulating. In addition, falling prices in the housing market, made it more difficulty to recover the investment in defaulted loans. These two processes, in our stylized model, correspond to increasing $p$ and increasing $c$, respectively. In both cases, one expects a sharp transition, for intermediate vales of $B$, from the state where the vast majority trades without gathering information on the underlying assets, to a situation where most of the agents actually perform independent credit analysis (see Fig. 3).

It can be argued that default probabilities were grossly under-estimated by rating agencies. This was partly due to misaligned incentives arising from the fact that rating agencies were paid by the very issuers of the securities they were rating. This would suggest, within the naïve picture of the crisis provided by our model, that investors were basing their choice of whether to adopt the rule or not on the basis of a hypothetical value of $p$ which was lower than the real one. Eventually, however, the disclosure of information on defaults of sub-primes and revelation of losses in financial institutions percolated through the market, which quickly realigned investors' beliefs (i.e. $p$ ). This suggests that the increase in $p$ the perceived probability of toxicity, might have been sharp rather than gradual, in the crisis.

A further element worth mentioning again, relates to the cost of information. With the introduction of more and more innovations in financial engineering of securitization, financial products became more and more complex. The cost of assessing the quality of credit derivatives has in consequence, been increasing in the last decade. This made it even more relatively profitable to follow the rule of trading without conducting credit analysis as opposed to undertaking the latter ${ }^{13}$. Lastly, this raises the possibility of the emergence of a third strategy, which is simply not to participate in the market at all, if the cost of finding information is high and the value of underlying assets whether toxic or not is falling then traders may simply wish to become inactive. This would account for the "freezing" of the market for these assets. Nevertheless, there is still hope for the prospects of remedial regulation with the introduction of appropriate Pigovian taxes, as outlined by Morris and Shin (2008).

Finally, the argument of this paper can be summarized as saying that the following of simple but not irrational rules by market participants can lead a market into a fragile state in which the very justification of the rules is undermined. Small changes in the macroeconomic environment coupled with the contagious spread of behavioral rules can gradually but almost imperceptibly undermine the system. Unfortunately, the result of these gradual changes can be catastrophic at the aggregate level.

\footnotetext{
${ }^{13}$ The particular case discussed in Eq. (9) makes this point clear. Indeed, if the average cost $1 / \lambda$ of information increases, the phase transition line moves upwards.
} 


\section{References}

Acharya, V. V., Richardson, M. P., 2009. Causes of the financial crisis. Critical Review 21, 195-210.

Adrian, T., Shin, H. S., 2009. The shadow banking system: implications for financial regulation, federal Reserve Bank of New York Staff Report No. 382.

Akerlof, G., 1970. The market for 'lemons'. Quarterly Journal of Economics 84, 488-500.

Ashcraft, A. B., Schuermann, T., 2008. Understanding the securitization of subprime mortgage credit, federal Reserve Bank of New York Staff Report No. 318.

Cheung, L., Tam, C.-S., 2009. Role of credit in equity market booms and bust, hong Kong Monetary Authority Working Paper No. 04/2009.

Cooper, R. W., 1999. Coordination Games : Complementarities and Macroeconomics. Cambridge University Press, New York.

Dell'Ariccia, G., Igan, D., Laeven, L., 2008. The us subprime mortgage crisis: A credit boom gone bad? www.voxeu.org/index.php?q=node/905.

Dridi, R., Guaya, A., Renault, E., 2007. Indirect inference and calibration of dynamic stochastic general equilibrium models. Journal of Econometrics 136, 397-430.

Eichengreen, B., 2008. Origins and responses to the current crisis. CESifo Forum 4/2008.

Eichengreen, B., Mitchener, K., 2003. The great depression as a credit boom gone wrong, bIS Working Papers No. 137.

Fabozzi, F. J., Kothari, V., 2007. Securitization: the tool of financial transformation, yale ICF Working Paper No. 07-07.

Hall, A., Inoue, A., Nason, J. M., Rossi, B., 2009. Information criteria for impulse response function matching estimation of dsge models, economic Research Initiatives at Duke (ERID) Working Paper No. 29.

Hume, M., Sentance, A., 2009. The global credit boom: challenges for macroeconomics and policy. Journal of International Money and Finance 28, 1426-1461.

Financial Stability Forum, 2008. Report of the financial stability forum on enhancing market and institutional resilience. Tech. rep., Financial Stability Board.

U.S. Securities and Exchange Commission, 2009. Sec votes on measures to further strengthen oversight of credit rating agencies, http://www.sec.gov/news/press/2009/2009-200.htm. 
Morris, S., Shin, H. S., 2000. Rethinking multiple equilibria in macroeconomic modelling. In: Macroeconomics Annual. NBER.

Morris, S., Shin, H. S., 2008. Brookings Papers on Economic Activity. Brookings Institute Press, Washington, DC, Ch. Financial regulation in a system context, pp. 229-274.

Rajan, U., Seru, A., Vig, V., 2008. The failure of models that predict failure: Distance, incentives and defaults, chicago GSB Research Paper No. 08-19.

Rosser, J. B., 2000. From Catastrophe to Chaos : A General Theory of Economic Discontinuities. Kluwer Academic Publishers, Dordrecht.

Sabarwal, T., 2006. Common structures of asset-backed securities and their risks. Corporate Ownership and Control 1.

Shiller, R. J., 2008. The Subprime Solution: How Today's Global Financial Crisis Happened, and What to Do about It. Princeton University Press, Princeton.

Smaghi, L. B., 2010. From boom to bust: towards a new equilibrium in bank credit, http://www.ecb.int/press/key/date/2010/html/sp100129.en.html.

Weisbuch, G., Chenevez, O., Nadal, J.-P., Kirman, A., 1998. Advances in Self-Organization and Evolutionary Economics. Economica, Ch. A Formal Approach to Market Organization: Choice Functions, Mean Field Approximation and Maximum Entropy Principle, pp. $149-159$. 